\title{
BMJ Open Cross-sectional analysis of the prevalence and predictors of statin utilisation in Ireland with a focus on primary prevention of cardiovascular disease
}

\author{
Paula Byrne, ${ }^{1}$ John Cullinan, ${ }^{1}$ Catríona Murphy, ${ }^{2,3}$ Susan M Smith ${ }^{4}$
}

To cite: Byrne P, Cullinan J, Murphy C, et al. Cross-sectional analysis of the prevalence and predictors of statin utilisation in Ireland with a focus on primary prevention of cardiovascular disease. BMJ Open 2018;8:e018524. doi:10.1136/ bmjopen-2017-018524

- Prepublication history and additional material for this paper are available online. To view these files, please visit the journal (http://dx.doi.org/10. 1136/bmjopen-2017-018524).

Received 5 July 2017 Revised 20 December 2017 Accepted 11 January 2018
Check for updates

${ }^{1}$ National University of Ireland Galway, Galway, Ireland

${ }^{2}$ Dublin City University, Dublin, Ireland

${ }^{3}$ The Irish Longitudinal Study on Ageing (TILDA), Dublin, Ireland ${ }^{4}$ Royal College of Surgeons in Ireland, Dublin, Ireland

Correspondence to

Paula Byrne;

pbyrne82@gmail.com

\section{ABSTRACT}

Objective To describe the prevalence of statin utilisation by people aged over 50 years in Ireland and the factors associated with the likelihood of using a statin, focusing particularly on those using statins for primary prevention of cardiovascular disease (CVD).

Methods This is a cross-sectional analysis of cardiovascular risk and sociodemographic factors associated with statin utilisation from wave 1 of The Irish Longitudinal Study on Ageing. A hierarchy of indications for statin utilisation, consisting of eight mutually exclusive levels of CVD-related diagnoses, was created. Participants were assigned one level of indication. The prevalence of statin utilisation was calculated. The likelihood that an individual was using a statin was estimated using a multivariable logistic regression model controlling for cardiovascular risk and sociodemographic factors.

Results In this nationally representative sample $(n=5618)$ of community-dwelling participants aged 50 years and over, $1715(30.5 \%)$ were taking statins. Of these, $65.0 \%$ ( $57.3 \%$ of men and $72.7 \%$ of women) were doing so for the primary prevention of CVD. Thus, almost two-thirds of those taking statins did so for primary prevention and there was a notable difference between women and men in this regard. We also found that statin utilisation was highest among those with a prior history of CVD and was significantly associated with age (compared with the base category 50-64 years; $65-74$ years OR $1.38(95 \% \mathrm{Cl} 1.16$ to 1.65$) ; 75+0 \mathrm{R} 1.33$ (95\% Cl 1.04 to 1.69$)$ ), living with a spouse or partner (compared with the base category living alone; OR 1.35 (95\% Cl 1.10 to 1.65)), polypharmacy (OR 1.74 (95\% Cl 1.39 to 2.19)) and frequency of general practitioner visits (compared with the base category 0 visits per year; $1-2$ visits OR 2.46 (95\% $\mathrm{Cl} 1.80$ to 3.35$)$; $3-4$ visits OR 3.24 (95\% Cl 2.34 to 4.47$)$; 5-6 visits OR 2.98 (95\% Cl 2.08 to 4.26$) ; 7$ + visits OR 2.51 (95\% Cl 1.73 to 3.63)), even after controlling for clinical need. There was no association between using statins and gender, education, income, social class, health insurance status, location or Systematic Coronary Risk Evaluation (SCORE) risk in the multivariable analysis.

Conclusion Statin utilisation among those with no history of CVD accounted for almost two-thirds of all statin use, in part reflecting the high proportion of the population with
Strengths and limitations of this study

- Large, nationally representative sample of community dwelling adults with self-reported verified drug utilisation.

- Good agreement between self-reported prescription medication use and pharmacy dispensing records for this cohort has been reported.

- Breakdown of utilisation according to a hierarchy of diagnoses enabled analysis of primary/secondary prevention use.

- Self-reported doctor diagnoses and recall of general practitioner visits may be subject to recall bias.

- Some diagnostic criteria, previous SCORE results and discontinuation of statins could not be ascertained.

no history of CVD, although utilisation rates were highest among those with a history of CVD.

\section{INTRODUCTION}

\section{Background}

The last 30 years have seen a large increase in the utilisation of statins hydroxy-methylglutaryl ((HMG)-coenzyme A reductase inhibitors) for the primary and secondary prevention of cardiovascular disease (CVD). ${ }^{1-4}$ In Ireland, the number of statin patient treatment days per 1000 inhabitants increased between 2000 and 2003 by 192\%, the highest recorded increase in a study of nine European countries. ${ }^{1}$ By 2014, over $€ 50$ million was spent annually in Ireland on these medicines in State-funded purchases alone. ${ }^{5}$ While the ageing population in high-income countries has been cited as a driver of increased utilisation of statins, Wallach Kildemoes $e t$ al found that increasing treatment intensity, rather than population ageing, was almost exclusively responsible for this rise. ${ }^{6}$ 
Statins may be prescribed for those with known CVD (secondary prevention), diabetes and familial hypercholesterolaemia (primary prevention), as well as for those considered 'at risk' of CVD but who have not yet had an event (primary prevention). The clinical guidelines relevant to the cohort in this study were those of the European Society of Cardiology 2007, ${ }^{7}$ which recommended that those with established CVD and diabetes be considered as the highest risk group. All others were to be assessed using the SCORE risk assessment tool. ${ }^{8}$ If a person was found to be above a 5\% risk threshold (over 10 years) using this method, or if they had established CVD or diabetes, the total cholesterol (TC) level recommended was $4.5 \mathrm{mmol} / \mathrm{L}$ and/or a low-density lipoprotein (LDL) level of $2.5 \mathrm{mmol} / \mathrm{L}$.

There is some evidence that statins are underused in certain sections of the population ${ }^{9-12}$ and that statins are not targeted at those most likely to benefit. ${ }^{13} 14$ However, increases in statin prescribing may be linked to changing clinical guidelines, which have been identified as drivers of a process of medicalisation as they generally widen the definition of disease. ${ }^{15}$ Updates of guidelines have included changes to thresholds of blood cholesterol levels and to risk categorisation, which lead to recommendations for statin therapy to expanded numbers of people. In particular, the use of statins in people without previous CVD (primary prevention) has been the subject of controversy. ${ }^{16}{ }^{17}$ Some authors criticise the extrapolation of clinical guidelines to subgroups, such as women or the elderly, ${ }^{18}$ and those with diabetes, ${ }^{19}$ where the evidence of a favourable risk-benefit ratio may not be conclusive. Although some studies have analysed statin use by broad diagnostic groupings, ${ }^{41420}$ analysis by diagnostic indication, ${ }^{6}$ as well as by 'at-risk' categorisation, could increase knowledge of drug utilisation patterns. This, in turn, could help explain the drivers of increased utilisation and the extent to which statins are used in patients with lower CVD risk, where the benefits may be limited or where the harms of statins may outweigh those benefits, particularly in primary prevention of CVD. ${ }^{172122}$

Wallach Kildemoes et $a l^{6}$ constructed a hierarchy of indications for which statins were prescribed (see online supplementary appendix 1 , table A1). This hierarchy was based on european guidelines on the prevention of CVD, ${ }^{23}$ the most recent of which, at the time of data collection, were published in 2007. This consisted of eight mutually exclusive levels of markers of CVD-related diagnoses and diabetes. The indication for a person with several of the listed medical conditions was considered to be that which placed them highest on the hierarchy. For example, if a person had both a previous myocardial infarction (MI) and hypertension, they were stratified into the MI category, that being the higher-level indication.

\section{Objective}

The aim of this study was to describe the prevalence of statin utilisation by indication, age and gender, in community-dwelling adults in Ireland aged 50 years and older in the period 2009-2011, with a focus on primary prevention of CVD. This included an examination of those factors, in particular CVD-related diagnoses based on a hierarchy of indications, which are associated with increased statin utilisation. A secondary analysis was undertaken to examine statin utilisation based on the risk of developing CVD, as measured by the SCORE risk assessment tool.

\section{METHODS}

\section{Design}

The study used cross-sectional data from wave 1 (20092011) of The Irish Longitudinal Study on Ageing (TILDA). TILDA collects data on a nationally representative sample of community living adults aged 50 years and older in Ireland. ${ }^{24}$ This allowed us to examine self-reported drug utilisation rather than prescribing data, which may be a more accurate way of assessing drug use. Ethical approval for the TILDA study was received from the Trinity College Research Ethics Committee and all participants provided written informed consent. As our study comprised secondary analysis of TILDA data, which is anonymised, further participant consent or ethical approval was not required.

\section{Participants and setting}

Participants were selected using RAMSAM, a system for drawing a random sample from the Irish geodirectory. ${ }^{25}$ Participants took part in a face-to-face computer-aided personal interview (CAPI) in their home, followed by a health assessment either in their home or at a designated health centre. Figure 1 shows the flow chart of participants included in our analysis. Of the 8175 individuals within TILDA aged over 50 years, 5634 undertook a health assessment. Since diagnosis of familial hypercholesterolaemia was not clear from our data, we removed 16

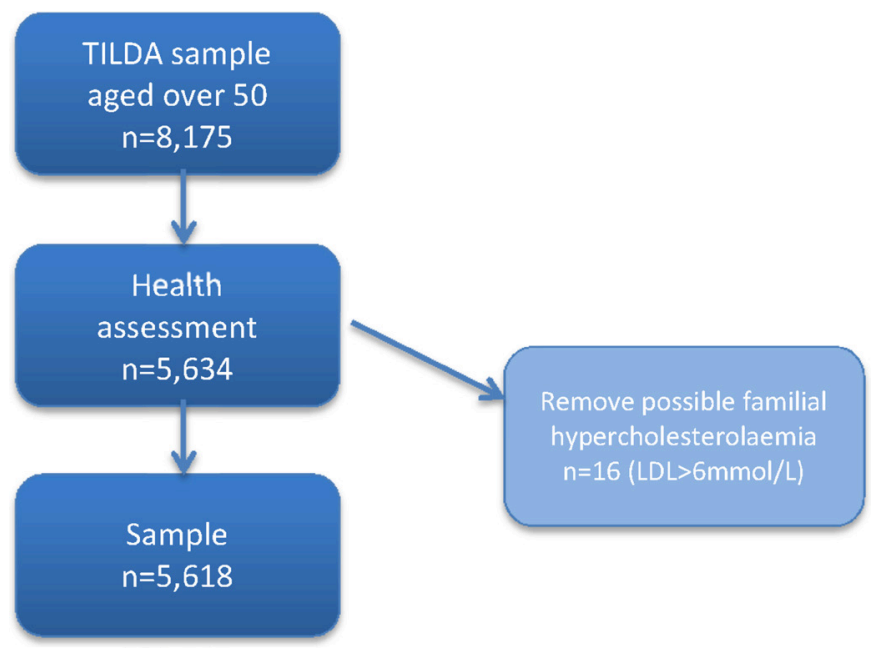

Figure 1 Flow chart of the number of participants included in the analysis. LDL, low-density lipoprotein. Source: Analysis of The Irish Longitudinal Study on Ageing (TILDA) wave 1 data. 
individuals whose LDL levels were $>6 \mathrm{mmol} / \mathrm{L}$ from the sample. This gave a final sample of 5618 individuals.

\section{Variables}

A full description of the variables used is presented in online supplementary appendix 2, table A2.1.

\section{Statin use}

Current medication use was recorded directly from respondents and was cross-checked by the interviewer who examined medication labels, which the participant showed them. Good agreement between self-reported prescription medication use and pharmacy dispensing records for this cohort has been reported. ${ }^{26}$

\section{Sociodemographic variables}

Sociodemographic data were collected by TILDA including age, gender and living arrangement. Six categories of both socioeconomic status and income levels were described. Educational status was described as 'primary or none', 'secondary' or 'third level or higher'. Participants were described as living either in Dublin city or environs, in another urban area or in a rural area.

\section{Healthcare variables}

Medical insurance status was described as 'no cover', 'medical insurance' for those with private medical insurance or 'medical card' for those whose medical costs were covered by the State. We recoded the number of GP visits into five categories-none, $1-2,3-4,5-6$ and 7 or more. Polypharmacy was recorded in the data as receiving five or more medications (excluding supplements) simultaneously. For the purpose of our analysis, we did not include statins as one of the five medications.

\section{Indication}

The indication for statin usage was determined during the CAPI. Participants were asked: "Has a doctor ever told you that you have any of the following conditions?" The conditions listed included: high blood pressure or hypertension; angina; a heart attack; congestive heart failure; diabetes or high blood sugar; a stroke; ministroke or transient ischaemic attack; high cholesterol; a heart murmur or any other heart trouble. An indication hierarchy was used as described by Wallach Kildemoes $e t a l$ and participants were assigned to the highest level of indication. The categories included in the hierarchy were MI, ischaemic heart disease (IHD), stroke, potential artherosclerotic conditions (PAC), diabetes, hypertension, high cholesterol and none of these conditions (no diagnosis).

\section{Analysis}

The prevalence of statin utilisation was calculated overall and for each age, gender and indication. A multivariable logistic regression model of whether an individual was taking a statin or not was estimated, controlling for cardiovascular indication and sociodemographic factors. This provides, for each covariate, the odds of statin use for one category of the covariate relative to another category, adjusting for all other covariates in the model. In particular, we estimated a stepwise (backward selection) model and applied a $10 \%$ significance level for removal. This means that we removed the variable with the greatest $\mathrm{P}$ value, one at a time, until all remaining variables had a $\mathrm{P}$ value $<10 \%$ threshold. The choice of variables included in the initial model was influenced by the data available in TILDA, as well as previous research, some of which had found significant associations between statin use and educational status, ${ }^{27}$ gender, ${ }^{14} 2027$ age, ${ }^{4} 28$ socioeconomic status, ${ }^{10} 2028$ number of GP visits, ${ }^{10}$ polypharmacy $^{29} 30$ and indication. ${ }^{1014}$ Other research found non-significant associations between statin use and marital status. ${ }^{27}$ Survey weights supplied by TILDA were applied to reduce non-response bias. The derivation of these weights is described in online supplementary appendix 2 . The characteristics used for calibration were age, sex and education, sourced from the Quarterly National Household Survey 2010 compiled by the Irish Central Statistics Office. ${ }^{31}$ Maximum missing data were $<1 \%$.

The SCORE tool was used to assess 10-year risk of a fatal CVD event in participants without established CVD or diabetes aged 50-64 years, stratified as either above or below a 5\% risk threshold. ${ }^{8}$ A multivariable logistic regression model was also used to examine how statin utilisation related to SCORE risk, controlling for cardiovascular indication, healthcare utilisation and sociodemographic factors.

The statistical software Stata/MP V.13.1 was used to conduct the analyses.

\section{RESULTS}

The characteristics of the sample are described in table 1.

\section{Prevalence according to age and gender}

Table 2 shows descriptive analyses for prevalence by indication and age. Within this sample of 5618 people, $30.5 \%$ were currently taking statins. Online supplementary appendix 2, tables A2.2, A2.3 show corresponding data for females and males, respectively, showing that higher proportions of men $(32.5 \%)$ than women $(28.8 \%)$ take statins (the 95\% CIs for these groups do not overlap). Table 2 also shows the prevalence of statin use in each age category for our sample. Statin utilisation increased monotonically with age; $22.6 \%$ of those aged $50-64$ years, $41.1 \%$ of those aged $65-74$ years and $45.6 \%$ for those aged 75 years or more. The increased use of statins with increasing age was observed in each gender category (see supplementary appendix 2, tables A2.2, A2.3), with lower proportions of women than men taking statins in each age category.

\section{Prevalence according to indication}

Table 2 shows, for example, that of the 250 people who have had MI, 185 are taking statins. This means that $74 \%$ of those who have had MI take statins. As the proportion of people who have had MI is low in the population, this 


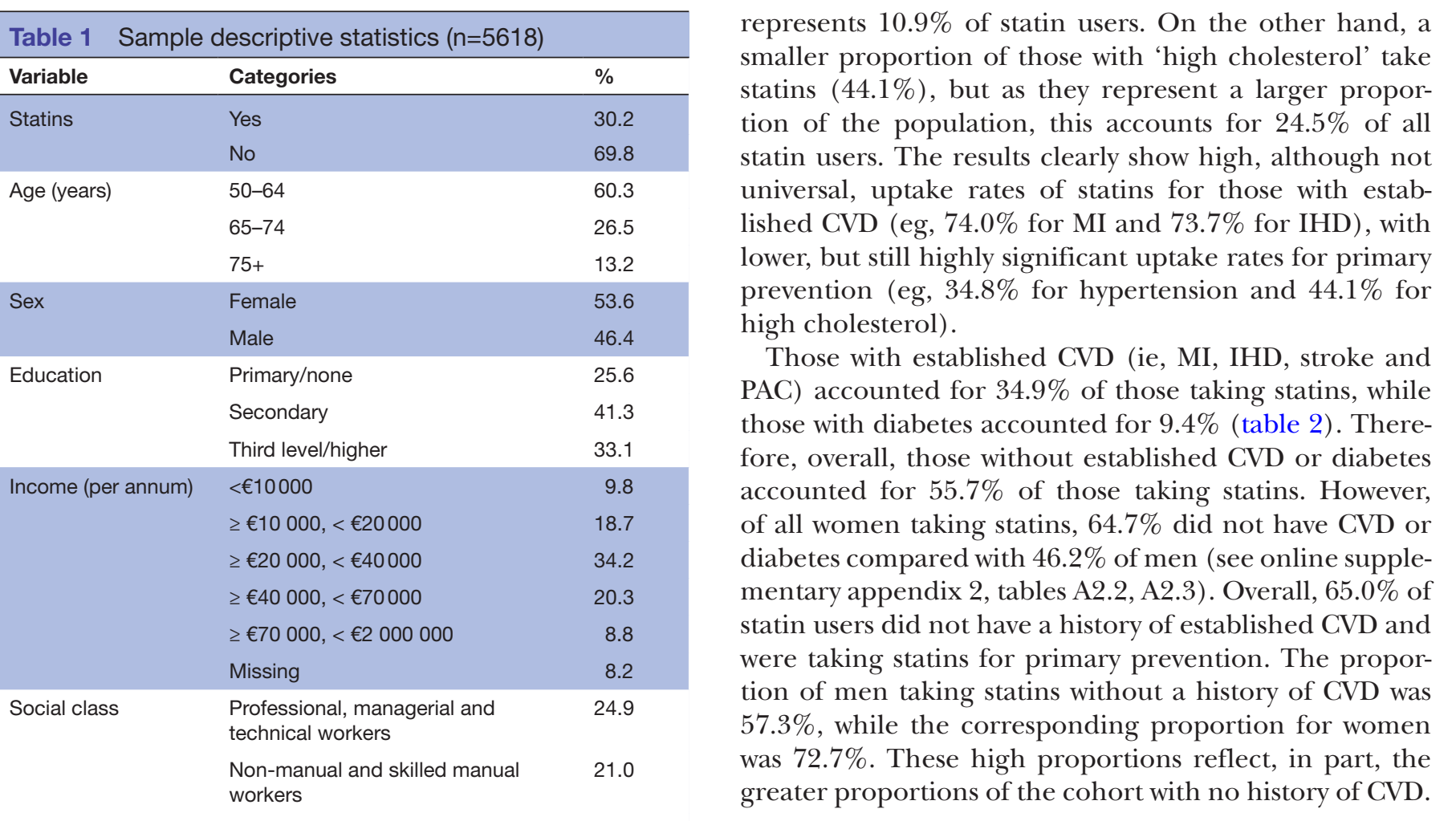

Semi-skilled and unskilled workers

Farmers

5.7

Not applicable

26.3

Unknown and refused

10.6

\begin{tabular}{|c|c|c|}
\hline \multirow[t]{3}{*}{ Insurance } & No cover & 10.4 \\
\hline & Medical insurance & 43.6 \\
\hline & Medical card & 46.0 \\
\hline \multirow{5}{*}{$\begin{array}{l}\text { General practitioner } \\
\text { visits }\end{array}$} & 0 & 12.6 \\
\hline & $1-2$ & 36.9 \\
\hline & $3-4$ & 26.6 \\
\hline & $5-6$ & 11.5 \\
\hline & $7+$ & 12.4 \\
\hline \multirow[t]{2}{*}{ Polypharmacy } & No & 80.0 \\
\hline & Yes & 20.0 \\
\hline \multirow[t]{3}{*}{ Lives with } & Living alone & 60.3 \\
\hline & Living with spouse/partner & 26.5 \\
\hline & Living with others & 13.2 \\
\hline \multirow[t]{3}{*}{ Location } & Dublin city or town & 26.3 \\
\hline & Another town or city & 27.3 \\
\hline & Rural area & 46.5 \\
\hline \multirow[t]{8}{*}{ Indication } & Myocardial infarction & 4.5 \\
\hline & Ischaemic heart disease & 3.2 \\
\hline & Stroke & 2.7 \\
\hline & Potential atherosclerotic conditions & 8.7 \\
\hline & Diabetes & 5.0 \\
\hline & Hypertension & 23.0 \\
\hline & High cholesterol & 17.0 \\
\hline & $\begin{array}{l}\text { No cardiovascular disease-related } \\
\text { diagnosis }\end{array}$ & 36.0 \\
\hline
\end{tabular}

Source: Analysis of The Irish Longitudinal Study on Ageing wave 1 data.

\section{Factors associated with statin utilisation}

Table 3 presents the estimated ORs obtained for each variable included in the final multivariable logistic regression model, adjusting for all other variables in the model.

Overall, those aged 65-74 years were more likely to be prescribed a statin than those aged 50-64 years (OR $1.38 ; 95 \%$ CI 1.16 to 1.65 ), as were those in the oldest age bracket, 75 and over (OR 1.33; 95\% CI 1.04 to 1.69).

The number of times a person reported visiting a GP in the previous year was predictive of the likelihood of taking a statin relative to those who had not reported visiting a GP in the previous year (table 3). Polypharmacy, defined as taking five or more medications, was also strongly predictive of statin utilisation (OR 1.74; 95\% CI 1.39 to 2.19). People who were living with a spouse or partner were more likely than those living alone to be taking a statin (OR $1.35 ; 95 \%$ CI 1.10 to 1.65 ). The odds of taking statins for those with a diagnosis of MI was, as expected, relatively high compared with those without MI. All indications were statistically significant except for the IHD category.

The ORs for socioeconomic variables such as income, social class and education level were not found to be statistically significant, nor were ORs for gender, health insurance status or whether the person lived in a rural or urban area.

\section{SCORE analysis}

SCORE risk was calculated in those without GVD or diabetes whose LDL and/or TC levels were above the recommended thresholds $(n=3551)$. Eighteen per cent of those whose SCORE result was $\geq 5 \%$ were taking statins; $17 \%$ of those with a 


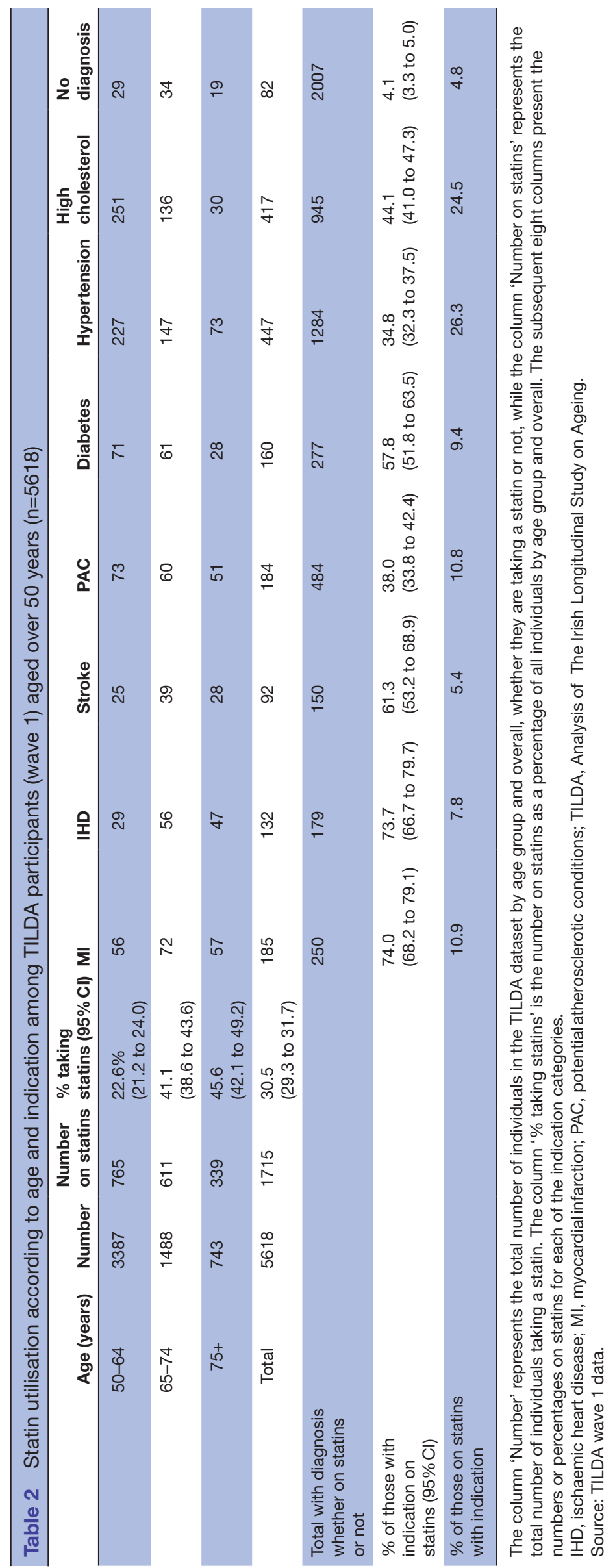

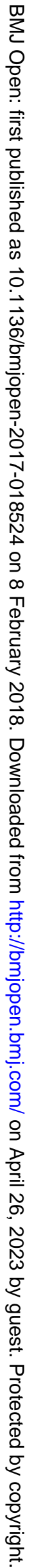


Table 3 Adjusted ORs of statin use from multivariable logistic regression model

\begin{tabular}{|c|c|c|c|}
\hline & OR & $P$ value & $95 \% \mathrm{Cl}$ \\
\hline \multicolumn{4}{|l|}{ Age (years) } \\
\hline 50-64 (base) & 1.00 & - & - \\
\hline $65-74$ & 1.38 & $<0.000$ & 1.16 to 1.65 \\
\hline $75+$ & 1.33 & 0.022 & 1.04 to 1.69 \\
\hline \multicolumn{4}{|l|}{ GP visits } \\
\hline 0 (base) & 1.00 & - & - \\
\hline $1-2$ & 2.46 & $<0.000$ & 1.80 to 3.35 \\
\hline $3-4$ & 3.24 & $<0.000$ & 2.34 to 4.47 \\
\hline $5-6$ & 2.98 & $<0.000$ & 2.08 to 4.26 \\
\hline $7+$ & 2.51 & $<0.000$ & 1.73 to 3.63 \\
\hline \multicolumn{4}{|l|}{ Polypharmacy } \\
\hline No & 1.00 & - & - \\
\hline Yes & 1.74 & $<0.000$ & 1.39 to 2.19 \\
\hline \multicolumn{4}{|l|}{ Lives } \\
\hline Alone (base) & 1.00 & - & - \\
\hline With spouse/partner & 1.35 & 0.004 & 1.10 to 1.65 \\
\hline With other & 0.95 & 0.640 & 0.76 to 1.18 \\
\hline \multicolumn{4}{|l|}{ Indication } \\
\hline MI (base) & 1.00 & - & - \\
\hline IHD & 0.98 & 0.948 & 0.59 to 1.64 \\
\hline Stroke & 0.51 & 0.009 & 0.31 to 0.84 \\
\hline PAC & 0.25 & $<0.000$ & 0.17 to 0.36 \\
\hline Diabetes & 0.50 & 0.002 & 0.33 to 0.77 \\
\hline Hypertension & 0.21 & $<0.000$ & 0.15 to 0.31 \\
\hline High cholesterol & 0.44 & $<0.000$ & 0.31 to 0.64 \\
\hline None of above & 0.03 & $<0.000$ & 0.02 to 0.04 \\
\hline Observations & \multicolumn{3}{|c|}{5528} \\
\hline Pseudo- $R^{2}$ & \multicolumn{3}{|c|}{0.2474} \\
\hline
\end{tabular}

The model is a stepwise (backward selection) multivariable binary logistic model, applying a 10\% significance level for removal. This means that only variables found to be statistically significant at the $10 \%$ level are included in the final model.

$\mathrm{IHD}$, ischaemic heart disease; MI, myocardial infarction; PAC, potential atherosclerotic conditions; TILDA, Analysis of The Irish Longitudinal Study on Ageing.

Source: TILDA wave 1 data.

SCORE of $<5 \%$ were taking statins (results not shown). However, it was not possible to interpret whether their SCORE risk level had been altered by statin utilisation nor could we ascertain what proportion in either risk group had potentially discontinued statins previously used.

In a separate multivariable model using the subsample of those without CVD or diabetes whose LDL and/ or TC levels were above the recommended thresholds, the SCORE risk category was not found to be statistically significantly related to taking a statin (results not presented).

\section{DISCUSSION}

\section{Key results}

We found that almost one-third of adults over 50 in this Irish cohort were taking statins. Almost two-thirds of these took statins for the primary prevention of CVD, but there was a notable difference between men and women. Almost three-quarters of women taking statins were doing so for primary prevention, compared with just over half of men. Prevalence of statin utilisation was found to increase with age.

Diagnostic indication was a predictor for increased likelihood of taking statins, with those with a history of MI, as expected, having the highest prevalence of statin utilisation. However, although the indication hierarchy used implied an ordering of indications corresponding to priorities for statin treatment, the likelihood of utilising a statin did not uniformly follow this order. Both the diagnoses 'diabetes' and 'high cholesterol' were found to have higher odds than warranted according to the hierarchy. However, it should be noted that this may be due to the numbers being small in some indication categories, leading to wide CIs, and thus the disparity in ordering should not be overinterpreted. Polypharmacy, frequency of GP visits and living arrangements were also significantly associated with the likelihood of taking a statin, while controlling for all other variables in the model.

The 2007 European Society of Cardiology clinical guidelines recommended that those with a SCORE of over 5\% be considered for statin treatment. ${ }^{728}$ This study found that less than a quarter of those above this threshold were using statins, as were one-fifth of those below. This may indicate that GPs or some other doctors initiating statin therapy do not use SCORE to risk assess their patients, but due to the limitations of our data it is difficult to interpret if this is the case.$^{32}$ A recent UK study of a primary care database found that most patients initiated on statins did not have a risk score recorded. While statins were initiated in $27.5 \%$ of clinical encounters and a risk score was recorded in $80 \%$ of all encounters, only $7.5 \%$ of encounters recorded both a risk score and subsequent statin initiation. ${ }^{33}$

\section{Strengths and limitations}

A strength of our analysis was that it was conducted on a large, nationally representative sample of community-dwelling adults, aged over 50 years in Ireland. Recording medication use directly from respondents with verification allows a closer examination of real-life usage compared with dispensing data that may not account for some elements of non-adherence. Survey weights were applied in the multivariable analysis to reduce potential bias from non-response in the TILDA data collection. This means that our findings are therefore more likely to be representative. These factors will allow for the generalisation of our findings to community living adults aged 50 years and over in Ireland. Our study will therefore be useful for cross-country comparisons of statin utilisation, as well as the patterns by which these drugs are prescribed. The breakdown of utilisation according to indication will inform the debate on 
the appropriateness of statin prescribing in subgroups of gender and age, diagnostic indications and those who fall into the primary and secondary prevention categories.

The study is limited in that it relies on self-reported doctor diagnoses and recall of the number of GP visits, which may be subject to recall bias. When constructing our indication hierarchy, the reported diagnosis of 'any other heart trouble' could not be used and so we may have underestimated the prevalence of those within the secondary prevention category. The diagnostic category "potential atherosclerotic conditions' may include diagnoses that are not atherosclerotic in origin. Also, the diagnostic category 'peripheral arterial disease' could not be ascertained due to limitations of the data gathered in TILDA. We have no information on those who have declined or discontinued statins and it is known that poor adherence to statins is common. ${ }^{28}$ We could not distinguish those with type I and type II diabetes. This is relevant as the 2007 guidelines distinguish between these groups. ${ }^{23}$ However, numbers of people with type 1 diabetes are relatively small compared with those with type 2 in the age group over 50 years. Although diagnosis of familial hypercholesterolaemia was not clear in the data, we removed those whose LDL levels were $>6 \mathrm{mmol} / \mathrm{L}$ from the sample. As this comprised 16 people this would not have affected results. Finally, it should be noted that given the cross-sectional nature of our data and the possibility of residual confounding, the results from our multivariable analysis should be considered as statistical associations rather than causal effects.

\section{Interpretation}

\section{Primary and secondary prevention}

While there is higher prescribing of statins for those with established CVD as would be expected, our finding that a large proportion of statins are used for the primary prevention of CVD is in line with international findings that the distribution of statin prescribing has shifted towards those at the lower end of the indication hierarchy. ${ }^{3}{ }^{34}$

Previous Irish research, using a subsample of TILDA data (aged 50-64years), found that despite clinical guidelines recommending the use of statins in those with CVD or diabetes, treatment prevalence was considered low in these groups, at $69 \%$ and $57 \%$, respectively. ${ }^{9}$ In addition, this previous study found a low level of treatment prevalence in those without CVD and diabetes, but whose SCORE was $\geq 5 \%$. Both findings are in line with the current study. However, by stratifying participants into the indication hierarchy, our study allowed those in the 'primary prevention' group to be analysed in greater detail.

Overall, $28.8 \%$ of women and $32.5 \%$ of men in our cohort were taking statins. We found that the majority $(65.0 \%)$ of our cohort was utilising statins for primary prevention of CVD, with a notable difference between men $(57.3 \%)$ and women $(72.7 \%)$.

\section{Age}

Our study showed that the odds of statin usage were higher at older age groups compared with the base category aged
50-64 years. This was similar to findings in Denmark, ${ }^{18} \mathrm{New}$ Zealand $^{28}$ and the UK, ${ }^{10} 14$ except that a decrease in utilisation was found in these studies in the oldest age groups.

\section{Socioeconomic factors}

In line with a previous Irish study, ${ }^{9}$ we did not find education level, social class, income or whether the person had medical insurance or a medical card to be statistically significant predictors of statin usage. An exception was found in the previous study for those at high SCORE risk, who were twice as likely to be taking statins if eligible for a medical card.

Conflicting findings about statin utilisation and socioconomic factors have been reported in studies from other countries. ${ }^{410} 11202728$ These differences may be a result of differences in access and entitlements within health systems, as well as differing social, political and cultural contexts. ${ }^{35}$ Countries may vary in reimbursement regulation, ${ }^{127} 28$ type of insurance cover (such as Medicaid, Medicare and private insurance in the USA) ${ }^{11}$ clinical guideline recommendations, ${ }^{14}$ local medical and patient culture as well as differences in demand from patients in differing socioeconomic groups. ${ }^{128}$

\section{Number of GP visits}

Controlling for indication, a person was more likely to be using a statin if they had visited their GP in the previous year than if they had not. The estimated OR increased with number of GP visits until three to four visits and decreased thereafter, although there was considerable overlap in the 95\% CIs for different frequencies of GP visits. In their study of factors influencing the prescribing of statins in the UK, $\mathrm{Wu}$ et al ${ }^{10}$ found that statin prescribing increased with number of blood pressure measurements, a proxy for GP visits and perception of CVD risk. However, the highest number of GP visits described was four or more and their study may have shown a similar pattern to ours were the number of visits stratified in a similar manner.

\section{Polypharmacy}

Polypharmacy, commonly defined as the use of five or more regular medicines, was found to be a strong predictor of statin prescription. In other words, controlling for clinical indication, a person receiving five or more medicines (excluding statins) was more likely to be taking a statin. A recent Irish study found that the prevalence of polypharmacy in those over 65 years in 2012 was $60 \%,{ }^{36}$ and that statins were the drug category prescribed to the highest number of individuals. Another study reported that lipid-modifying drugs were the most commonly reported medication class $(69 \%)$, along with antithrombolytics, used by those reporting polypharmacy. ${ }^{37}$ Our finding raises questions as to why, controlling for diagnostic indication, someone receiving five or more medicines would be more likely to receive a statin. This could be based on differences in patient preferences as well as challenges to following clinical guidelines for patients with 
multimorbidity, which is closely linked with polypharmacy. ${ }^{38}$ Some studies have found an association between polypharmacy and increased likelihood of statin use $\mathrm{e}^{29} 30$ and adherence to statins, ${ }^{39} 40$ while others found that people subject to polypharmacy were less likely to adhere to medicines, including statins. ${ }^{41}$ Further qualitative research is recommended to explore this finding.

\section{Indication hierarchy}

The indication hierarchy implied an ordering of indications ${ }^{6}$ corresponding to priorities described in European guidelines. ${ }^{23}$ However, our analysis showed that the likelihood of using a statin did not exactly follow this order of prescribing priority. Both 'high cholesterol' and 'diabetes' were found to have higher odds than warranted according to the hierarchy, although again we acknowledge the caveat that this may be due to small numbers for some indication categories. Those with high cholesterol were more likely to receive statins than those with PAC and hypertension, whereas those with SCOREs over the recommended risk threshold had low levels of statin utilisation. This could imply an overemphasis on high cholesterol, a single risk factor, as a reason to prescribe rather than prescribing based on overall risk assessment. This finding corresponds with those from the USA, ${ }^{14}$ Norway, ${ }^{27}$ the $\mathrm{UK}^{10}$ and Australia. ${ }^{42}$

In our study, $57.8 \%$ of people with diabetes were taking statins and they accounted for $9.4 \%$ of prevalent statin users. This finding was similar to previous Irish $^{9}$ and Danish findings. ${ }^{22}$ Two US studies found that $48 \%{ }^{10}$ of 'eligible diabetics' and $52 \%{ }^{14}$ of people with both diabetes and hyperlipidaemia were taking statins. In those without a diagnosis of hyperlipidaemia, this fell to $12 \%$.

\section{CONCLUSION}

This study describes statin utilisation in a representative sample of people aged over 50 years in Ireland. We show high, although not universal, uptake rates of statins for those with established CVD, with lower, but still highly significant uptake rates for primary prevention. Given the ongoing debate on the appropriateness of statin use in primary prevention, ${ }^{22} 4344$ it is significant that such a large proportion of Irish users fall into this category, particularly women. In addition, the possible focus on hyperlipidaemia as a reason for prescribing instead of overall CVD risk may indicate an overemphasis on this single risk factor. ${ }^{14}{ }^{42}$ Polypharmacy, controlling for indication, was strongly associated with statin use. This finding warrants further investigation.

Statins are widely prescribed and command a large share of drug expenditure in Ireland and other countries. An increasingly larger proportion of the population are using statins, and this is becoming very resource intensive and arguably unsustainable. The evidence base for statin use in various diagnostic categories varies ${ }^{1922}$ and thus, the benefit-to-risk ratios for each also vary. There have been concerns about the medicalisation of risk factors such as mild hypercholesterolaemia. ${ }^{45}$ Various commentators have pointed out that the benefits of prescribing a medicine must outweigh the harms ${ }^{46}$ and that the budget impact of thresholds for treatment needs to be considered. ${ }^{47}$ However, uncertainties abound when deciding on cost-effective treatment thresholds. ${ }^{48}{ }^{49}$ It would therefore seem appropriate to consider whether widespread use of statins in some of these diagnostic categories represents the best use of scarce resources, particularly in low-risk groups. ${ }^{50}$

The debate on the appropriate use of statins for primary prevention of CVD is ongoing and highly topical. ${ }^{17} 431-54$ At the heart of this debate is the question as to whether the benefits of taking statins outweigh the harms and costs for patients in the primary prevention category. The first step towards answering this question is to consider current utilisation and indication for use, as we have done, which provide important contextual information for the debate on statin use.

Acknowledgements The authors would like to thank TILDA for providing access to the data, in particular Hugh Nolan and Neil O'Leary. In addition, although the data were not used in final analysis, the authors would like to thank Kathleen Bennett and the HSE-PCRS for access. Marie Therese Cooney wrote the code we used for SCORE risk calculation and Ronan Conroy from RCSI assisted in the use of this code. In addition, the authors would also like to thank Daniela Rohde, SPHeRE scholar, for her help.

Contributors PB was the lead researcher and involved in the design, implementation and analysis and reporting of the study. JC, CM and SMS provided substantial contributions to the conception, design, analysis and reporting of the work. PB, JC, CM and SMS have all read and approved the final manuscript and agree to be accountable for all aspects of the work.

Funding This study is part of PB's PhD, which is funded by the SPHeRE HRB structured $\mathrm{PhD}$ programme. TILDA, the original study on which this is based, is funded by the Irish Department of Health, Irish Life and Atlantic Philanthropies. CM reports grants from the Health Research Board during the conduct of the study (grant no. HRB/ICE 2012/7).

Competing interests None declared.

Patient consent Obtained.

Ethics approval Ethical approval for the TILDA study was received from the Trinity College Research Ethics Committee and all participants provided written informed consent. TILDA has both publicly available data, which can be accessed as described in the section 'Data sharing', as well as additional data that are available only for research purposes. These data can be accessed on application to and approval by TILDA, which was granted to PB for the purposes of this paper.

Provenance and peer review Not commissioned; externally peer reviewed.

Data sharing statement Researchers interested in using TILDA data may access the data for free from the following sites: Irish Social Science Data Archive (ISSDA) at University College Dublin http://www.ucd.ie/issda/data/tilda/; Interuniversity Consortium for Political and Social Research (ICPSR) at the University of Michigan: http://www.icpsr.umich.edu/icpsrweb/ICPSR/studies/34315

Open Access This is an Open Access article distributed in accordance with the Creative Commons Attribution Non Commercial (CC BY-NC 4.0) license, which permits others to distribute, remix, adapt, build upon this work non-commercially, and license their derivative works on different terms, provided the original work is properly cited and the use is non-commercial. See: http://creativecommons.org/ licenses/by-nc/4.0/

(c) Article author(s) (or their employer(s) unless otherwise stated in the text of the article) 2018. All rights reserved. No commercial use is permitted unless otherwise expressly granted. 


\section{REFERENCES}

1. Walley T, Folino-Gallo P, Stephens P, et al. Trends in prescribing and utilization of statins and other lipid lowering drugs across Europe 1997-2003. Br J Clin Pharmacol 2005;60:543-51.

2. Feely J, McGettigan P, Kelly A. Growth in use of statins after trials is not targeted to most appropriate patients. Clin Pharmacol Ther 2000;67:438-41.

3. Kildemoes HW, Støvring H, Andersen M. Driving forces behind increasing cardiovascular drug utilization: a dynamic pharmacoepidemiological model. Br J Clin Pharmacol 2008;66:885-95.

4. DeWilde S, Carey IM, Bremner SA, et al. Evolution of statin prescribing 1994-2001: a case of agism but not of sexism? Heart 2003;89:417-21.

5. Health Service Executive Primary Care Reimbursement Service. Primary care reimbursement scheme. statistical analysis of claims and payments 2013. Dublin: Health Service Executive Primary Care Reimbursement Service, 2014.

6. Wallach Kildemoes H, Hendriksen C, Andersen M. Drug utilization according to reason for prescribing: a pharmacoepidemiologic method based on an indication hierarchy. Pharmacoepidemiol Drug Saf 2012;21:1027-35.

7. Graham I, Atar D, Borch-Johnsen K, et al. European guidelines on cardiovascular disease prevention in clinical practice: executive summary. Fourth joint task force of the European society of cardiology and other societies on cardiovascular disease prevention in clinical practice (constituted by representatives of nine societies and by invited experts). Eur J Cardiovasc Prev Rehabil 2007;14(suppl):E1-40.

8. Conroy RM, Pyörälä K, Fitzgerald AP, et al. Estimation of ten-year risk of fatal cardiovascular disease in Europe: the SCORE project. Eur Heart J 2003;24:987-1003.

9. Murphy C, Bennett K, Fahey T, et al. Statin use in adults at high risk of cardiovascular disease mortality: cross-sectional analysis of baseline data from The Irish Longitudinal Study on Ageing (TILDA). BMJ Open 2015;5:e008017.

10. Wu J, Zhu S, Yao GL, et al. Patient factors influencing the prescribing of lipid lowering drugs for primary prevention of cardiovascular disease in UK general practice: a national retrospective cohort study. PLoS One 2013;8:e67611.

11. Condliffe $S$, Link $C$, Townsend $B$. Who receives statins? Variations in physician prescribing patterns for patients with coronary heart disease. Appl Econ Lett 2010;17:1647-52.

12. Feely J. The therapeutic gap-compliance with medication and guidelines. Atherosclerosis 1999;147(Suppl 1):S31-7.

13. Teeling M, Bennett $\mathrm{K}$, Feely $\mathrm{J}$. The influence of guidelines on the use of statins: analysis of prescribing trends 1998-2002. Br J Clin Pharmacol 2005:59:227-32

14. Johansen ME, Green LA, Sen A, et al. Cardiovascular risk and statin use in the United States. Ann Fam Med 2014;12:215-23.

15. Moynihan RN, Cooke GP, Doust JA, et al. Expanding disease definitions in guidelines and expert panel ties to industry: a crosssectional study of common conditions in the United States. PLoS Med 2013;10:e1001500.

16. Abramson JD, Rosenberg HG, Jewell N, et al. Should people at low risk of cardiovascular disease take a statin? BMJ 2013;347:f6123.

17. Goldacre B, Smeeth L. Mass treatment with statins. BMJ 2014;349:g4745.

18. Wallach Kildemoes $\mathrm{H}$, Vass $\mathrm{M}$, Hendriksen $\mathrm{C}$, et al. Statin utilization according to indication and age: a Danish cohort study on changing prescribing and purchasing behaviour. Health Policy 2012;108:216-27.

19. Chang YH, Hsieh MC, Wang CY, et al. Reassessing the benefits of statins in the prevention of cardiovascular disease in diabetic patients- a systematic review and meta-analysis. Rev Diabet Stud 2013;10:157-70.

20. Kitzmiller JP, Foraker RE, Rose KM. Lipid-lowering pharmacotherapy and socioeconomic status: Atherosclerosis Risk In Communities (ARIC) surveillance study. BMC Public Health 2013;13:1

21. Golomb BA, Evans MA, Dimsdale JE, et al. Effects of statins on energy and fatigue with exertion: results from a randomized controlled trial. Arch Intern Med 2012;172:1180-2.

22. Wallach-Kildemoes $\mathrm{H}$, Stovring $\mathrm{H}$, Holme Hansen $\mathrm{E}$, et al. Statin prescribing according to gender, age and indication: what about the benefit-risk balance? J Eval Clin Pract 2016;22:235-46.

23. Graham I, Atar D, Borch-Johnsen $\mathrm{K}$, et al. European guidelines on cardiovascular disease prevention in clinical practice: executive summary. Atherosclerosis 2007:194:1-45.

24. Barrett A, Burke H, Cronin H, et al. Fifty plus in Ireland 2011: first results from The Irish Longitudinal Study on Ageing (TILDA). Dublin: Trinity College Dublin, 2011.
25. Whelan BJ. Ransam-random sample design for Ireland. Econ Soc Rev 1979:10:169-74

26. Richardson K, Kenny RA, Peklar J, et al. Agreement between patient interview data on prescription medication use and pharmacy records in those aged older than 50 years varied by therapeutic group and reporting of indicated health conditions. J Clin Epidemiol 2013;66:1308-16.

27. Selmer R, Sakshaug S, Skurtveit $\mathrm{S}$, et al. Statin treatment in a cohort of 20212 men and women in Norway according to cardiovascular risk factors and level of education. $\mathrm{Br} \mathrm{J}$ Clin Pharmacol 2009;67:355-62.

28. Norris $\mathrm{P}$, Horsburgh $\mathrm{S}$, Becket $\mathrm{G}$, et al. Equity in statin use in New Zealand. J Prim Health Care 2014;6:17.

29. Bertolotti M, Franchi C, Rocchi MB, et al. Prevalence and determinants of the use of lipid-lowering agents in a population of older hospitalized patients: the findings from the REPOSI (REgistro POliterapie Società Italiana di Medicina Interna) study. Drugs Aging 2017;34:311-9

30. Watanabe JH, Bounthavong M, Chen T, et al. Association of polypharmacy and statin new-user adherence in a veterans health administration population: a retrospective cohort study. Ann Pharmacother 2013;47:1253-9.

31. Whelan BJ, Savva GM. Design and methodology of the Irish longitudinal study on ageing. J Am Geriatr Soc 2013;61(Supp 2):S265-68

32. Byrne $\mathrm{D}, \mathrm{O}$ 'Connor $\mathrm{L}$, Jennings $\mathrm{S}$, et al. A survey of GPs awareness and use of risk assessment tools and cardiovascular disease prevention guidelines. Ir Med J 2015;108:204-7.

33. Finnikin $\mathrm{S}$, Ryan $\mathrm{R}$, Marshall $\mathrm{T}$. Statin initiations and QRISK2 scoring in UK general practice: a THIN database study. Br J Gen Pract 2017;67:e881-87.

34. Feely J, Bennett K. Epidemiology and economics of statin use. Ir Med J 2008;101:188-91.

35. Walley T, Folino-Gallo P, Schwabe U, et al. Variations and increase in use of statins across Europe: data from administrative databases. BMJ 2004;328:385-6.

36. Moriarty F, Hardy C, Bennett K, et al. Trends and interaction of polypharmacy and potentially inappropriate prescribing in primary care over 15 years in Ireland: a repeated cross-sectional study. BMJ Open 2015;5:e008656.

37. Richardson K, Moore P, Peklar J, et al. Polypharmacy in adults over 50 in Ireland: opportunities for cost saving and improved healthcare. Dublin: The Irish Longitudinal Study on Ageing, Lincoln Place, Trinity College Dublin, 2012.

38. Wallace E, Salisbury C, Guthrie B, et al. Managing patients with multimorbidity in primary care. BMJ 2015;350:h176.

39. Wawruch M, Zatko D, Wimmer G, et al. Patient-related characteristics associated with non-persistence with statin therapy in elderly patients following an ischemic stroke. Pharmacoepidemiol Drug Saf 2017;26:201-7.

40. Grant RW, O'Leary KM, Weilburg JB, et al. Impact of concurrent medication use on statin adherence and refill persistence. Arch Intern Med 2004;164:2343-8

41. Mohammed S, Arabi A, El-Menyar A, et al. Impact of polypharmacy on adherence to evidence-based medication in patients who underwent percutaneous coronary intervention. Curr Vasc Pharmacol 2016:14:388-93.

42. Schilling C, Mortimer D, Dalziel K, et al. Using Classification and Regression Trees (CART) to identify prescribing thresholds for cardiovascular disease. Pharmacoeconomics 2016;34:195-205.

43. Godlee F. Statins and the BMJ. BMJ 2014;349:95038.

44. Fairman KA, Curtiss FR. Does medicalization of life imperil health? Expanding indications for diagnosis and treatment of chronic disease". J Manag Care Pharm 2011:17:469-80.

45. Gotzsche PC. Commentary: Medicalisation of risk factors. BMJ 2002;324:890-1.

46. Fineberg $\mathrm{H}, 2012$. Avoidable care: magical thinking and modern medicine. Avoiding Avoidable Care, Cambridge, MA. http:// avoidablecare.org/the-healthcare-imperative/

47. Epstein D, García-Mochón L, Kaptoge S, et al. Modeling the costs and long-term health benefits of screening the general population for risks of cardiovascular disease: a review of methods used in the literature. Eur J Health Econ 2016;17:1041-53.

48. Macdonald $\mathrm{H}$, Loder $\mathrm{E}$. Too much medicine: the challenge of finding common ground. BMJ 2015;350:h1163.

49. Busfield J. Assessing the overuse of medicines. Soc Sci Med 2015;131:199-206.

50. Taylor F, Huffman MD, Macedo AF, et al. Statins for the primary prevention of cardiovascular disease. Cochrane Database Syst Rev 2013:CD004816. 
51. Godlee F. Statins: we need an independent review. BMJ 2016;354:i4992.

52. Hawkes N. Risks in the balance: the statins row. BMJ 2014;349:g5007.
53. Hawkes $\mathrm{N}$. Results of investigation into statin side effects due by end of year. BMJ 2015;350:h957.

54. Wise J. Englands chief medical officer asks for review of drug evaluation in wake of statins controversy. BMJ 2015;350:h3300. 